\title{
Circular Migration and Human Mobility - An Observation
}

\author{
B. Chandra Mohan Patnaik \\ Associate Professor, Management, School of Management -KIIT University, Bhubaneswar, Odisha, India \\ Email: bcmpatnaik@gmail.com \\ Ipseeta Satpathy \\ Professor, Management, School of Management -KIIT University, Bhubaneswar, Odisha, India \\ Email: ipsita@ksom.ac.in \\ Anirban Mandal \\ Research Scholar, School of Management, KIIT University, Bhubaneswar, Odisha, India \\ Email: anirban3009@gmail.com
}

\section{Doi:10.5901/mjss.2015.v6n1s1p133}

\section{Abstract}

The paper tries to focus on circular migration concept from developmental point of view. People are expected to move from one place to other when they found some favourable circumstances for living, especially during agricultural lean period when their level of income decreases. It is generally believed that only those people opting for circular migration who have a very strong bonding with their own place. This bonding has some social significance as well as economic impact also. The process also helps them to acquire knowledge which they can utilize in their own place provided adequate infrastructure and support activities are available. Thus, to make this type of movement economically viable from the society's point of view, government should involve in keeping this movement restricted within migrant's own place by creating desired infrastructure support. Otherwise chances are there that this movement may become permanent one and will create pressure on urban economy.

Keywords: Circular Migration, Mobility, Skill Development, PURA, NSDC

\section{Introduction}

Migration is considered as the movement of people from one geographical region to another which may be temporary or permanent in nature. The reasons for migration may vary country or region wise but the exiting socio economic condition in migrant's place of origin plays a crucial role in to take a decision to migrate from one place to another. Various migration literatures indicate that people migrate for better living conditions, better job opportunities or to live in a better environment. Sometimes, migrants move individually or if things permit they intend to move along with their family members. Thus, migration is a selective process which involves role of the family members also. Side by side decision to migrate also depends on prevailing socio, economical and demographic characteristics of that place.

When people decided to move, the type of movement becomes an important decision making process. A migrant either moves permanently or they may decide to move temporarily. Thus, type of movement depends on the typical cost benfit analysis that the migrants do in their sub - conscious mind. In this paper we would like to focus on temporary migration and circular migration is part of this type of migration decision, when people decides to move only for a specific period of time and then again come back to their original place when situation improves.

\subsection{Research Objective}

The present study would like to highlight on the following objectives:

- To identify the consequences of circular migration in terms of financial and professional leverage

- To recommend specific policy decisions so that circular migration flow can be utilized for the overall positive development in both the place of origin as well as place of destination 


\section{Research Methodology}

The present study focus on circular migration only, the major problem is to identify the target respondents due to lack of available data from a recognize source. The Government of India published Census data in every 10 years interval. The latest data in this series was published in the year 2011. But that data covers only people who are migrating in general and the reasons for migration. This data is not focus on specific type of migration and its consequences.

Given this limitations we have decided to gone for exploratory research and take the help of various literatures to study the secondary sources of informations which discussed the reasons for circular migration and its consequences. Our objective is to judge how far these factors help to provide a better understanding about the concept and consequences of circular migration in Indian context.

\section{Literature Review}

As discussed above circular migration is generally preferred by those who have a very strong bonding with their respective place of origin and they are shifting their place of work temporarily mainly due to economic downturn. Various literatures suggest this trend. The MEN annual policy report 2010 highlights on the fact that this type of migration which often comes under the temporary migration strategy has three distinct benefits, viz. benefits for to the destination countries as it reduces the labour shortages, benefits for the migrants if they are able to garner adequate knowledge related to their work which increases their skills and third and most importantly, remittances send by these migrants also increases the economic well being of origin country. But this positive approach will become successful with lots of conditions, like destination country should have labour requirement and the migrants should be in a position to garner knowledge. So, if we see circular migration as a poverty removing strategy then we need to understand that migrants taking their decision to move after considering various needs like, social security, job opportunity and survival opportunity (IZA Report, 2012). Thus, it can be termed as a risk diversification strategy from migrant's point of view. In some literatures it is mentioned that remittances play a crucial role in overall development but that it is often observed that flow of remittances don't get any meaningful investment opportunities as origin area lacks it. So, most of the time, the money is getting spend in unwanted luxury item (Graeme Hugo, 2013). Like lots of benefits circular migration is not free from any kind of disturbances. As observed in various literatures circular migrants are not the winner all the time as they don't have the choice regarding jobs, change of employers, and timing of jobs (Piyasiri Wickramasekara, 2011). Sometimes, the cost of movement is so high, that people take loan to migrate even for a temporary period of time and if they failed to get proper job, then this loan becomes none performing. Thus, the very basic purpose of taking loan is not being fulfilled rather it becomes a burden on them (Abu S. Shonchoy, 2011). In their paper Circular Migration in India, Kate Bird and Priya Deshingkar observed that circular migration in India is mainly found among extremely poor, living in remote rural areas (Bird \& Deshingkar, 2009). This also justifies the fact that here cost of movement is obviously a crucial factor, which extremely poor people can't afford. Thus, instead of permanent migration they opted for circular migration.

\section{Migration \& Human Mobility}

Global Human Development Report 2009, Overcoming Barriers: Human Mobility \& Development argued that when people decided to move they intended to consider lots of factor related to superior standard of living, superior healthcare facilities for the migrants as well as their family members, superiors educational facilities of their children etc. Human beings continuously looking for these superior opportunities and if any specific place gives them that opportunity they would like to consider the place as their place of destination. This may lead to internal migration or international migration and the nature of migration depends on the capability and ability of the migrants in terms of their knowledge, job related skills and most importantly cost of moving.

The Global Human Development Report 2009 indicated that nearly 1 billion people move from one place to another and among them the largest are internal migrants specifically move within the country in terms of number the report estimated that it is approximately 740 million people. If we look at the socio economic background of the migrants most of them are labour migrants but some of them are internally displaced mainly because of political violence. The report also suggested that these people choose to place themselves in those areas where regions have same or higher growth in terms of Human Development Index (HDI). ${ }^{1}$

Although overall migration may yield some positive dimensions towards the life of migrants still tradeoffs exists.

1 Global Human Development Report, 2009 
This tradeoff mainly arises in terms decision dilemma. It was observed that most of the migrants are often confused between which type migration decision will benefit them in the near future. Given the option either they can opt for permanent migration or they can go for temporary migration or circular migration process. In the first case, the migrant's decision may be influenced if lots of pull factor may attract them to a new destination. However, push factors like political violence can be influential in taking this kind of permanent migration decision. On the other hand, if any migrants decided to go for temporary migration then some other factors like, village land holding, responsibility of household, lack of skill to adjust themselves in urban areas plays an influential role in this case.

\subsection{Circular Migration}

Generally migration can be broadly categorizes into two broad categories, viz. permanent migration and temporary migration. Circular migration is part of temporary migration which is our topic of discussion in this article.

Concept of circular migration is quite old. During 1960s and 1970s the term was first used in the anthropological and demographic literature on urbanization, rural development and internal migration in developing countries. The reason for which the term is associated with developing countries is because of income differentials between developed and developing countries.

The concept of circular migration mainly related to nature of job that the prospective migrants are doing. In rural areas people mostly depend on agriculture which in turn depends on proper rainfall and other climatic conditions in that place. Because of that reason nature of job is also not permanent. This typical working condition directly affects their earning and subsequently their standard of living also. It get rid off from this situation people decided to move to a new destination till the time the situation is restored in their place of origin. This movement helps them to sustain their livelihood even during the lean period. Interestingly, this type of short term movement does not restricted to marginal agricultural workers only. People having their own land also decided to shift for a short period of time only because neither they have sufficient capacity to invest in scientific irrigation system nor they have other nonfarm income generation activities in their own place. When situation improves, these workers come back to their own places. Because of improved situation labour demand also increases, so the income differentials reduced in place of origin. Obviously, this increase income does not matched with the wage that they are getting in urban areas, but still if we are factoring moving and staying cost then this rural agricultural wage during prosperity period is become a pull factor for them to move from urban to rural areas. Apart from income, detachment from family members also plays an influential role for this kind of short or circular migration. As this process continues for over a period of time then this will be termed as circular migration.

However if this kind of movement becomes repetitive in nature then there may exist a chance that these migrants may permanently stay in place of destination. Provided during these movements they are able acquire sufficient skills to survive in the urban areas along with their family and the migrants may not able to implement the acquired skills in their own place because of lack of opportunity in their own place.

Circular migration thus able to reduce inequalities and foster development provided the movement of the people can be correlates with favourable policy implementation. This can be achieved when migrants get proper socio economic benefits in the place of destination as well as they are able to retain strong bonding with the people belongs to place of origin. Not only that it will is help to reduce uneven pressure on the urban counterpart when their lack of demand for jobs mostly in informal sectors. Thus, the process of movement can be termed as a win - win situation for both the areas as the movement from rural to urban areas creates temporary shortage of workforce, but this shortage of workforce happens during lean period in agriculture. On the other hand the increasing pressure on urban areas can be reduced when they returned back to their respective areas during good seasons. Thus, frequent movement possibility between two areas can be an important ingredient for circular migration.

Although circular migration is one of the important types of human mobility, in the present situation this particular movement becomes more relevant because of two factors, viz. easy and less costly transport options and mobile connectivity. Pradhan Mantri Gram Sadak Yojana (PMGSY) which was launched on 25th December, 2000 to provide all weather connectivity in rural areas, has given the momentum in this regard. The programme proposed to connect all areas with a population of 500 persons and above in the plain areas and 250 persons and above in hill states, tribal areas and the desert areas. This will cover 1.67 lakh unconnected habitations and development of 3.71 lakh km. of roads in those areas. This mammoth programme immensely benefits the poor and because of improved connectivity the frequent movement can be possible, which is a prerequisite for successful circular migration. This will also help them to earn more by moving quickly in the high earning regions and spend the amount in low cost margin areas, hence would maximize their purchasing power. 
The other prerequisite which is communication is also become a viable option for poor household. The penetration of mobile connectivity and affordability is the main reason for that. Mobile phone today is not a luxury product; it becomes a part and parcel of human beings. So, the problems of keeping in touch with the family members during migration are not a problem now days. Not only that these migrants become habituated with the technology and using it as a mode of sending remittances through banking channels. This easy connectivity thus started playing a very crucial role in circular migration also.

Thus, if migrants find easier mobility for traveling both in and out destination the more likely migrants will opt for a circular strategy over permanent settlement. Family members who remain in the sending area encourage circular migration. High education, home ownership and labour market attachment in the destination encourage permanent settlement. Circular migration also reduces the risk of losing human capital to brain drain.

\subsection{Benefits of Circular Migration}

The most important benefit that circular migration can give to destination areas is the flexibility to quickly overcome the skill gaps which sometimes become a costly affair when employers try to recruit people from own areas. Most of the time it was observed that the demand for circular migrants arises mostly in informal sectors with low job satisfaction and low wage which the urban counterpart often do not wish to join because of their exposure to other job market. Thus, these sectors which contribute nearly $60 \%$ of the country's overall economic contribution remains depended on circular migrants. It can also reduce the pressure of surplus labour in origin areas and provide the local economy with an influx of new skills and capital that migrants bring back with them. For the migrants, circulation migration offers the opportunity to gain experience and earn higher wages while retaining valued connections in the home country.

It is also argued that circular migration, in which migrants are provided the opportunity to re-enter the host society at a later date, encourages the return of the migrant, hence discouraging overstay.

But these limitations come with some degree of negative aspects also.

The above study indicates that circular migration process has dual positive impact, one for the migrants only and the other for both the areas where migrant moves, i.e. place of origin and place of destination. But this kind of movement comes with lots of criticism also. In various literatures it was observed that the so called guaranteed benefits which the migrants suppose to get in terms of skill development and better working environment and higher salaries are questionable. The reason for this is very simple. As employers know that these people are not going to stay for a long period of time and the nature of the job is part time, they are not willing to invest too much amount of money and resources for their skill development. So, people with some experience in the related field are able to land up with proper job. Rest of the people work as a helper and earn a very low wage, which does not fulfill their objective of migration. Even the political factors sometimes discourage their chance of getting proper exposure as this policy initiative may prove fatal if the temporary migrants decided to stay permanently once they acquire the skills and started demanding higher wage.

The argument that circular migration benefits the country of origin in terms of application of new skills by migrants is also not a solid ground to prove that this type of migration is beneficial for all the parties concerned. Because this benefit is entirely depends on what type of training and the nature of training and skill development the migrants are able to acquire during this entire process. As discussed earlier due to temporary nature of the job, most of the employers do not get incentive to invest in their skill development. Not only that within a short period of time it is very difficult to gain sufficient knowledge which can be implement by the migrant in their own place.

The impact on the migrant therefore differs according to the approach to temporary and circular migration taken in the host society: i.e. upon whether it is the host society who controls how the temporary and circular migration is managed - i.e. the conditions of entry, stay and return; or whether the migrant is able to control when they stay and go, creating a 'spontaneous' or 'non-managed' form of migration.

\section{Conclusion}

The potential benefits of circular migration may act negatively if it is found that these migrants are engaging themselves in works which far below than their skill level. This will certainly not benefit any stakeholders in the entire process. Proper policy mechanism should be developed in this regard where migrants' skills can be utilized properly for the overall development of the migrants as well as the society where they belong. Another important fact which we must consider that after gaining sufficient exposure in a related job does these migrants able to implement it properly when they returning back? The answer is obviously no. This is because even if they are willing to implement it neither they have infrastructure nor they have the resource to implement it. In case of India, Central Govt. tries to implement the PURA 
strategy which says Providing Urban Amenities in Rural Areas (PURA). It proposes that urban infrastructure and services be provided in rural areas to create economic livelihood opportunities outside the peripheral boundary of cities. This results into physical connectivity by providing roads, electronic and phone connectivity by providing communication network and knowledge connectivity by providing by establishing professional and technical institutions. Another such programmes like National Skill Development Corporation (NSDC), also working in the same direction. This NSDC programme trying to provide vocational education to school and college drop outs so that they become employable as there is a huge demand of skill workforce.

If these programmes can be implemented successfully then surely skill gap problem faced by the migrants can be eliminated. Not only that we can also restrict the movement of the people by providing adequate opportunities in rural areas which is lacking and which forcing these people to move out even for a short period of time.

Moreover, circular migration programmes of short duration increase the likelihood of non-recognition of qualifications, and therefore, would contribute little to skills gains by home areas.

Again the experiences of successful business creation by return migrants are mixed. It is also not clear whether these circular migrants are better at business and enterprise creation than permanent return migrants. An International Institute for Labour Studies-International Labour Organization (IILS-ILO) study on North Africa advocates circular migration on this ground, but the study fails to clarify whether these relate to circular migration or simple one shot return migration as defined above (IILS-ILO 2010). The general experience has been that much more than skills and entrepreneurship, it is the general economic and business environment at home that promotes successful business and employment generation by all migrants, as well as non-migrants.

A major issue is the implication of temporary and circular migration programmes for migrants' rights. There is no built in mechanism in circular migration programmes to protect migrant rights.

Europe Aid (2010: 5) mentions: "When temporary migration implies a series of contracts, migrants' rights may become an important issue" in view of absence of family unification, social security entitlements, and being tied to one employer. Since employers may not be willing to invest in career development and training of temporary foreign workers, "... circularity can jeopardise migrants' upward social mobility."

\section{References}

Abdur Rafique, Deeptima Massey \& Ben Rogaly (October 2006), Migration for Hard Work: Abu S. Shonchoy (2011), Seasonal Migration \& Micro Credit in the Lean Period: Evidence from Northwest Bangladesh; IDE Discussion Paper No. 294.

Amaresh Dubey, Richard Palmer - Jones \& Kunal Sen (July 2004), Surplus Labour, Social Structure \& Rural to Urban Migration: Evidence from Indian Data; Conference Paper Presented at the Conference on the 50th Anniversary of the Lewis Model.

Amelie F. Constant, Olga Nottmeyer \& Klaus F. Zimmermann (October 2012), The Economics of Circular Migration, Discussion Paper No. 6940, IZA.

Department for International Development Report (March 2007), Moving out of Poverty: Making Migration Work Better for Poor People.

Graeme Hugo (September 2013), What we Know about Circular Migration and Enhanced Mobility, Migration Policy Institute, No. 7 , September 2013

Kate Bird \& Priya Deshingkar (2009); Circular Migration in India, Policy Brief No. 4, Overseas Development Institute.

Piyasiri Wickramasekara (2011), Circular Migration a Triple Win or a Dead End; Discussion Paper No. 15, Global Union Research Work, International Labour Office, Geneva.

Priya Deshingkar \& Daniel Start (August 2003), Seasonal Migration for livelihoods in India - Coping, Accumulation \& Exclusion, Overseas Development Institute (Working Paper).

Robert E. B. Lucas (2007), Migration \& Rural Development; Journal of Agricultural \& Development Economics, Agricultural Development Economics Division (ESA) FAO, Volume 4, No. 1, 2007, pp. 99 - 122.

Robert Ssengonzi, Gordon F. De Jong \& C. Shannon (2002), The effect of female migration on infant and child survival in Uganda; Population Research and Policy Review 21, pp. 403 - 431.

S. M. Jawed Akthar \& N. P. Abdul Azeez (February 2012), Rural Employment Guarantee Programme \& Migration; ; Kurukshatra, Journal on Rural Development, Vol. 60, No. 4, pp. 11 - 15.

Sheena Mcloughlin etal (March 2011), Temporary and Circular Migration: Opportunities and Challenges; Working Paper No. 35, European Policy Centre.

Steven Vertovec (2007), Circular Migration: The Way Forward in Global Policy; Working Paper 4, International Migration Institute, University of Oxford.

Steven Vertovec (2007), Circular Migration: the way forward in global policy; Working Paper 4, International Migration Institute.

Temporary and Circular Migration: empirical evidence, current policy practice and future options in EU Member States, Report prepared by European Migration Network, September, 2011.

Zelina Sultana (December 2010), Impact of Monga on Rural Urban Migration: Its Socio Economic Consequences; ASA University Review, Vol. 4, No. 2, July - December 2010. 